\title{
Idiopathic pulmonary fibrosis and diabetes mellitus: a meta-analysis and systematic review
}

\author{
Le Bai ${ }^{1}$, Li Zhang ${ }^{1}$, Tingyu Pan ${ }^{1}$, Wei Wang ${ }^{1,2}$, Dian Wang ${ }^{1,2}$, Cassidy Turner ${ }^{3}$, Xianmei Zhou ${ }^{1,4^{*}}$ and Hailang He ${ }^{1,4^{*}}$
}

\begin{abstract}
Background: Idiopathic pulmonary fibrosis (IPF) is a chronic diffuse interstitial lung disease, of which the etiology has been poorly understood. Several studies have focused on the relationship between IPF and diabetes mellitus (DM) in the past years but have failed to reach a consensus. This meta-analysis aimed to examine the association between diabetes to IPF.

Methods: We accumulated studies investigating the association between DM and IPF from databases including Medline, Cochrane Library, Embase, Web of Science, and China National Knowledge Infrastructure. RevMan 5.3 and the Newcastle-Ottawa Scale (NOS) were utilized to analyze the data and assess the quality of the included studies. The value of odds ratio (OR) with $95 \%$ confidence interval (Cl) was used as the measure to estimate the risk of DM in IPF. Heterogeneity was assessed by $P^{2}$ statistics. We also performed subgroup analysis, meta-regression, and Egger's test for bias analysis.

Results: Nine case-control studies with 5096 IPF patients and 19,095 control subjects were included in the present meta-analysis, which indicated a positive correlation between DM and IPF (OR 1.65, 95\% Cl 1.30-2.10; $P<0.0001)$. Meta-regression and subgroup analysis negated the influence of covariates like cigarette smoking, age and gender, but the heterogeneity existed and could not be fully explained.
\end{abstract}

Conclusion: IPF and DM may be associated, but the causal relationship remains indeterminate till now. Further rigorously designed studies are required to confirm the present findings and investigate the possible mechanisms behind the effect of DM on IPF.

Keywords: Idiopathic pulmonary fibrosis, Diabetes mellitus, Meta-analysis, Systematic review

\section{Introduction}

Idiopathic pulmonary fibrosis (IPF) is a progressive and fatal pulmonary disease with an annual cumulative prevalence of 18.2 cases per 100,000 persons in America [1] while a median survival of only $3-5$ years $[2,3]$. IPF is characterized pathologically by proliferation and differentiation of lung fibroblasts. Cigarette smoking, age and gender, chronic viral infections, etc., are considered as risk factors of IPF [4]. In the past decade, the

*Correspondence: zhouxianmeijsszyy@163.com; lyghehailang@163.com ${ }^{1}$ Affiliated Hospital of Nanjing University of Chinese Medicine, Nanjing 210029, China

Full list of author information is available at the end of the article understanding of IPF pathogenesis has shifted from an inflammatory-driven process [5] to the hypothesis of aberrant activation of the alveolar epithelial cells [6]. Nevertheless, the exact etiology of IPF remains unclear.

In recent years, it has been observed that IPF patients are often additionally diagnosed with diabetes mellitus (DM), resulting in increased research interest in the correlation between these two diseases. Firstly, two earlier case-controls studies $[7,8]$ were successively conducted in Japan but obtained opposite conclusions. Subsequent clinical observational studies $[9,10]$ suggested that DM was likely to increased the risk of IPF, which inspired experiments related to antidiabetic treatment for IPF. Interestingly, using mice animal models, it was revealed original author(s) and the source, provide a link to the Creative Commons licence, and indicate if changes were made. The images or other third party material in this article are included in the article's Creative Commons licence, unless indicated otherwise in a credit line to the material. If material is not included in the article's Creative Commons licence and your intended use is not permitted by statutory regulation or exceeds the permitted use, you will need to obtain permission directly from the copyright holder. To view a copy of this licence, visit http://creativecommons.org/licenses/by/4.0/. The Creative Commons Public Domain Dedication waiver (http://creativeco mmons.org/publicdomain/zero/1.0/) applies to the data made available in this article, unless otherwise stated in a credit line to the data. 
that metformin could reverse established lung fibrosis [11-15], however, a post hoc analysis [16], which investigated the effect of combinations therapy in IPF (pirfenidone/pirfenidone + metformin), concluded that metformin had no effect on clinically relevant outcomes. Furthermore, another pooled analysis demonstrated that metformin might increase the risk of disease progression when in combination with proton pump inhibitors, angiotensin II receptor blockers or thyroid medications [17].

Due to the conflicting results in the existing studies, it remains controversial whether DM is truly correlated with IPF. Hence, in the present study, we conducted a meta-analysis and systematic review, aiming to assess the association between DM and the incidence of IPF.

\section{Materials and methods}

We performed meta-analysis and wrote this report referring to the Meta-analysis Of Observational Studies in Epidemiology (MOOSE) proposal [18] and the Preferred Reporting Items for Systematic Reviews and Meta-Analyses (PRISMA) statement [19].

\section{Literature search}

We searched databases including Medline, Cochrane Library, Embase, Web of Science and China National Knowledge Infrastructure. The following items were searched in databases as keywords or random words: "pulmonary fibrosis", "diabetes", "risk factors" and such searches were additionally filtered for articles published in any language leading up to September 30, 2020 (Complete search strategy presented in Appendix 1).

\section{Inclusion criteria and exclusion criteria}

Case-control studies or cohort studies were selected. The case groups were all diagnosed with IPF in accordance with clinical history, High-Resolution Computed Tomography (HRCT), and when available, lung biopsy. Also, a calculated measure of association between DM and IPF was required. Studies focusing on progression or prognosis of IPF and studies lacking general information about control groups were excluded.

\section{Data extraction}

Two researchers (L.B. and L.Z.) managed data extraction independently, reviewing the title, abstract, and full text of each article, and discussed or consulted a third researcher (T.P.) when disputations arose. The following are included: (1) basic information of each study including author, publication year, study design, etc.; (2) characteristics of case and control groups; (3) diagnostic methods of DM and IPF; (4) the number of diabetics in case and control groups; and (5) potential sources of biases.

\section{Quality assessment}

The Newcastle-Ottawa Scale (NOS) was used for quality assessment of included studies, covering three domains: selection of groups, comparability of groups and ascertainment of exposure [20]. The NOS score ranges from 0 to 9 stars and studies that receive 5 stars or more are regarded as high quality. We evaluated the diagnostic criteria of IPF and DM in each study for the possibility of selection bias. Cigarette smoking, age, gender, environmental exposure and genetic factors, which may induce IPF and bring about information bias, were deemed as covariates and all taken into consideration when estimating whether control subjects were adequately selected.

\section{Statistical analysis}

In our meta-analysis, odds ratio with $95 \%$ confidence interval $(95 \% \mathrm{CI})$ was used as the effect measure. Heterogeneity was assessed by $I^{2}$ statistics and random effect model was chosen when heterogeneity was significant $\left(I^{2}>50 \%\right)$, otherwise, fixed effect model was selected. Forest plots were used to display the results from individual studies and pooled estimates, and $P<0.05$ were regarded as statistically significant. Trial Sequential Analysis (TSA) was used for estimate of evidence size and reliability of the conclusion [21, 22]. We also performed sensitivity and subgroup analyses to assess resources of heterogeneity. Meta-regression and Egger's test [23] were utilized for bias analysis. Data analysis was performed using RevMan 5.3, Stata 12, and TSA 0.9 beta.

\section{Results}

\section{Study selection and characteristics}

As is briefly illustrated in Fig. 1, out of the 1528 articles reviewed, 9 studies [7-10, 24-28] from 5 countries finally met our eligibility. All studies were case-control and distinguished as high-quality by NOS assessment. General population was selected as control groups in six studies [7, 8, 10, 25-27], one study included only healthy volunteers [24], and the remaining two $[9,28]$ included patients with other chronic pulmonary diseases. IPF was diagnosed based on clinical history, HRCT, and lung biopsy while diagnosis of DM could be established with any objective method such as fasting blood glucose or simple by clinical symptoms combined with clinical history. More details are displayed in Table 1.

\section{Meta-analysis}

A total of 5096 IPF cases and 19,095 control subjects were involved in the analysis (Fig. 2), which suggested a significant association between DM and IPF (OR 1.65, 

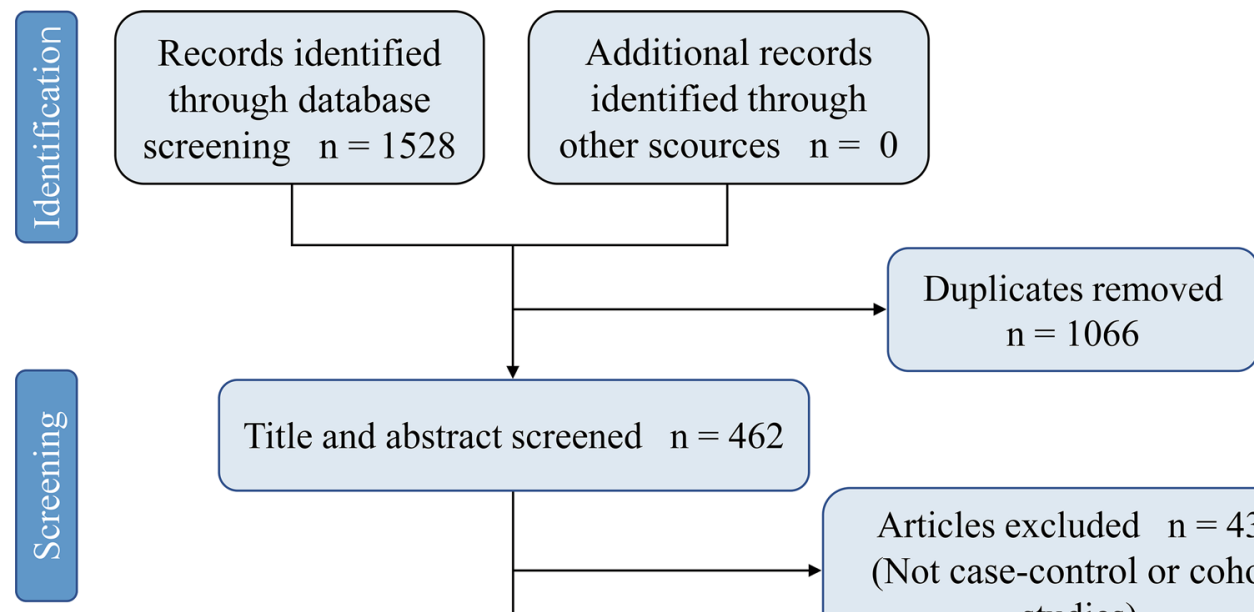

Title and abstract screened $\mathrm{n}=462$

Articles excluded $n=437$

(Not case-control or cohort studies)

Full-text assessment $\mathrm{n}=25$
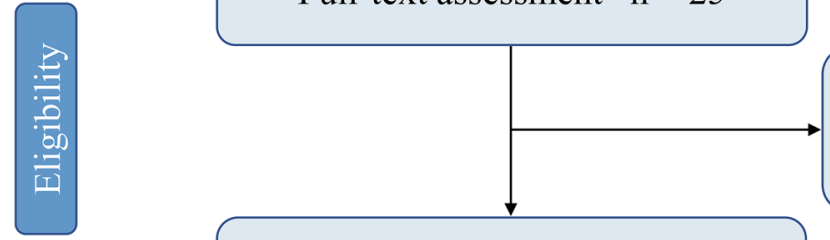

Article excluded $n=14$

(Aimed at development and prognosis of IPF ) Articles included in qualitative
synthesis $\mathrm{n}=11$
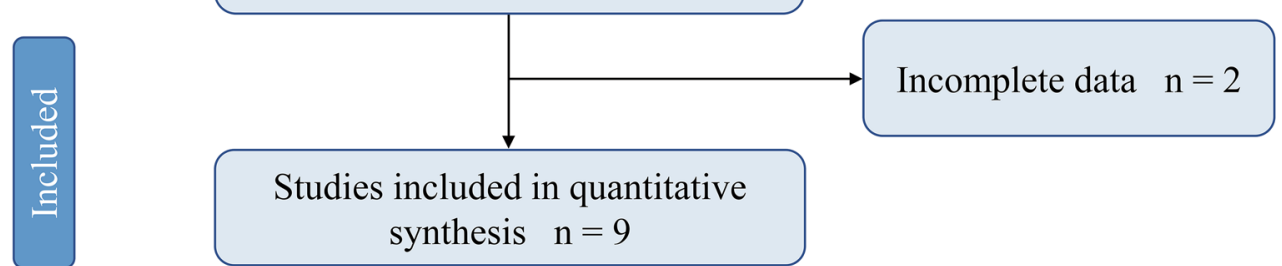

Studies included in quantitative synthesis $\mathrm{n}=9$

Fig. 1 The flow diagram of study selection

95\% CI 1.30-2.10; $P<0.0001)$, based on statistical reliability verified by the subsequent trial sequential analysis (Fig. 3). The heterogeneity was significant $\left(I^{2}=68 \%\right)$ with no obvious sources of biases found among the sensitivity analyses (Fig. 4). Therefore, we performed subgroup analyses to investigate factors that possibly contribute (Table 2). The result remained consistent in separate analyses regardless of community or hospital controls, and irrespective of diagnostic criteria of IPF/ DM or characteristics of control groups (healthy subjects, general population or patients with pulmonary disorders). When smoking status, age, and gender were accounted for in case and control groups, the heterogeneity still existed as before.

\section{Bias analysis}

All elements that could lead to IPF were considered as potential sources of biases. Firstly, cigarette smoking is a known risk factor for IPF [29] and in the five included studies [7, 24, 26-28], smokers or ex-smokers were much more in case groups than in controls. In the following subgroup analysis (Table 2), when we selected the other four studies [8-10, 25] in which the smoking habits between case and control groups were similar, the association remained statistically significant (OR 1.52, 95\% CI $1.05-2.19 ; P=0.02$ ), which coincided with the outcome of the meta-regression (Fig. $5, P=0.351$ ), suggesting that smoking was unlikely to distort the final results. Next, considering that age and gender are related to IPF despite 


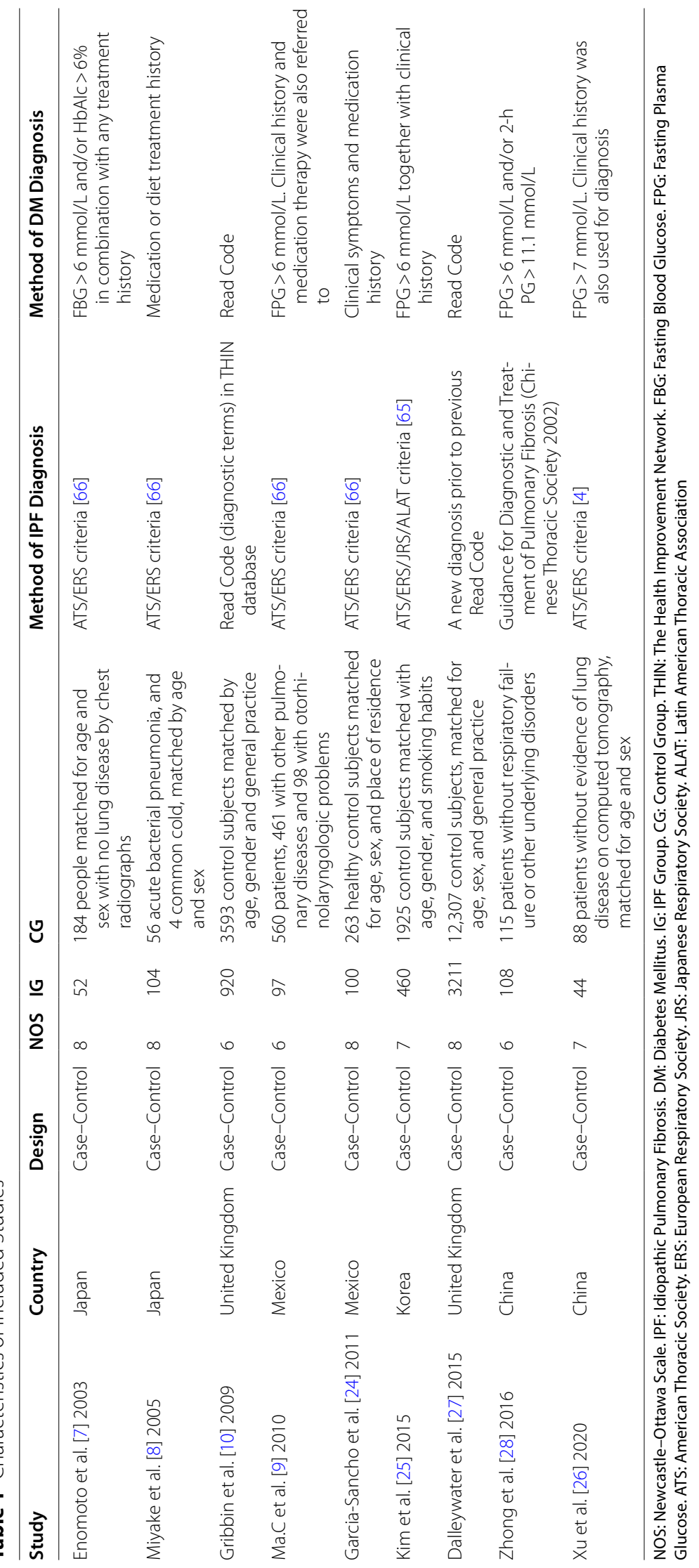




\begin{tabular}{|c|c|c|c|c|c|c|c|c|c|}
\hline \multirow{3}{*}{$\begin{array}{l}\text { Study or Subgroup } \\
\text { Cecilia Garcia-Sancho } 2011\end{array}$} & \multicolumn{2}{|c|}{ IPF+ } & \multicolumn{2}{|c|}{ IPF- } & \multirow[b]{2}{*}{ Weight } & Odds Ratio & \multirow{2}{*}{\multicolumn{2}{|c|}{$\begin{array}{c}\text { Odds Ratio } \\
\text { M-H, Random, } 95 \% \mathrm{Cl}\end{array}$}} & \\
\hline & $\mathrm{DM}+$ & Total & $\mathrm{DM}+$ & Total & & M-H, Random, $95 \% \mathrm{Cl}$ & & & \\
\hline & 30 & 100 & 50 & 263 & $10.7 \%$ & $1.83[1.08,3.09]$ & & $\longrightarrow$ & \\
\hline Jiang xu 2020 & 9 & 44 & 8 & 88 & $4.3 \%$ & $2.57[0.92,7.22]$ & & & \\
\hline Jonathan Gribbin 2009 & 89 & 920 & 275 & 3593 & $17.8 \%$ & $1.29[1.01,1.66]$ & & $=-$ & \\
\hline Ma.Cecilia García-Sancho Figueroa 2010 & 11 & 97 & 16 & 560 & $6.4 \%$ & $4.35[1.95,9.68]$ & & & \\
\hline Tatsuji Enomoto 2003 & 17 & 52 & 21 & 184 & $7.1 \%$ & $3.77[1.81,7.87]$ & & & \\
\hline William Dalleywater 2015 & 450 & 3211 & 1481 & 12307 & $21.1 \%$ & $1.19[1.06,1.33]$ & & - & \\
\hline Won-Young Kim 2015 & 90 & 460 & 300 & 1925 & $17.5 \%$ & $1.32[1.01,1.71]$ & & —— & \\
\hline Yoshihiro Miyake 2005 & 13 & 104 & 7 & 60 & $4.7 \%$ & $1.08[0.41,2.88]$ & & & \\
\hline Zhong Xie 2016 & 66 & 108 & 50 & 115 & $10.5 \%$ & $2.04[1.20,3.49]$ & & $\overline{-}$ & \\
\hline Total $(95 \% \mathrm{Cl})$ & & 5096 & & 19095 & $100.0 \%$ & $1.65[1.30,2.10]$ & & $\infty$ & \\
\hline Total DM+ & 775 & & 2208 & & & & & & \\
\hline \multicolumn{10}{|c|}{ Heterogeneity: $\mathrm{Tau}^{2}=0.07 ; \mathrm{Ch}^{2}=25.21, \mathrm{df}=8(\mathrm{P}=0.001) ; \mathrm{I}^{2}=68 \%$} \\
\hline Test for overall effect: $Z=4.12(P<0.0001)$ & & & & & & 0.1 & 0.5 & 2 & 10 \\
\hline
\end{tabular}

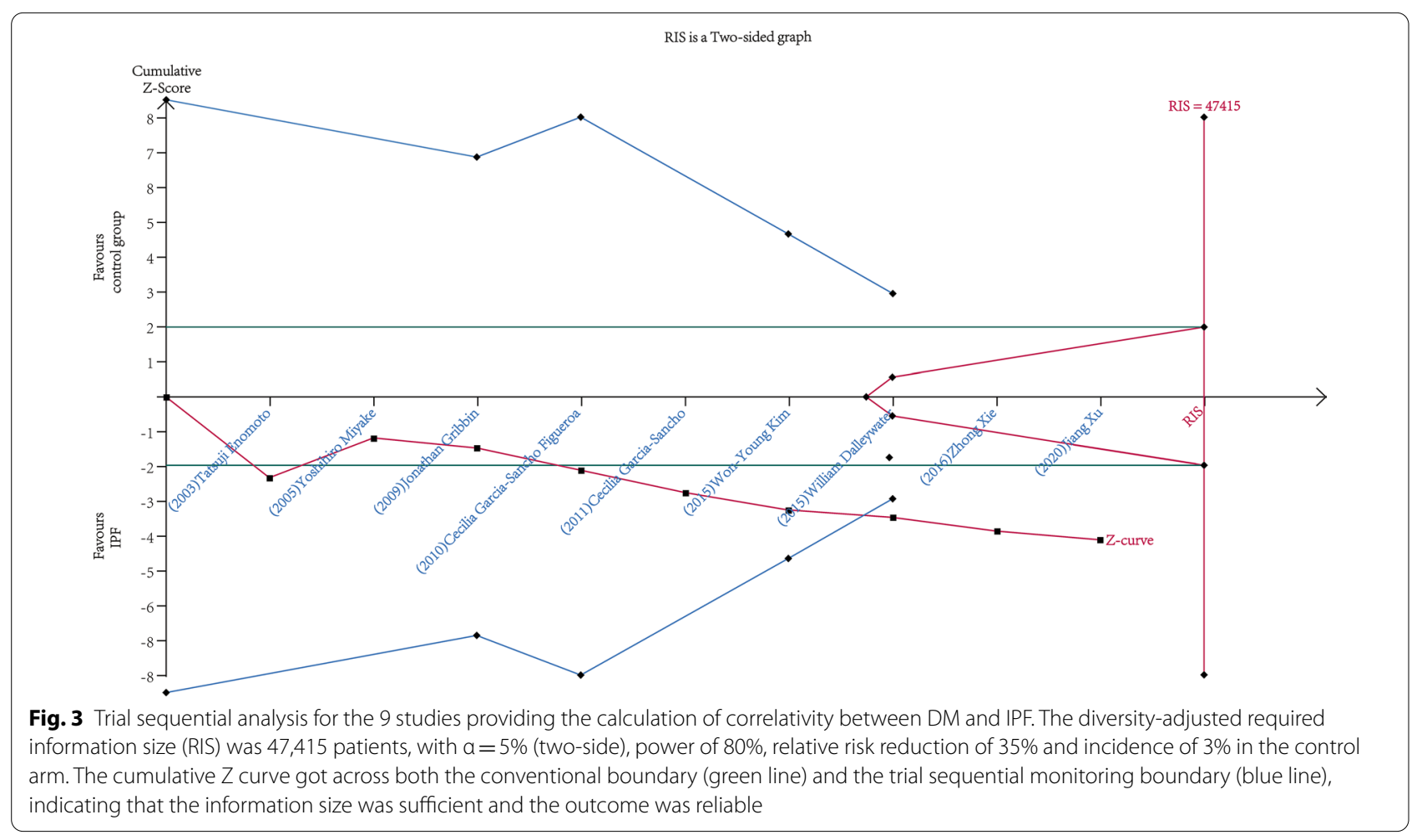

inexplicable reasons [4], seven studies [7, 8, 10, 24-27] in which these two factors were well-balanced were used to inform another analysis, yet again concluding that DM correlated with IPF (OR 1.43, 95\% CI 1.16-1.76; $P=0.0007)$. Still, there remained two potential sources of biases that the included literatures did not sufficiently address (Table 3). In light of a multicenter case-control study [30], environmental exposure was likely responsible for the incidence of IPF, which has been gradually acknowledged in recent years. Though three studies [8, 9, $24]$ took this into consideration, unfortunately, only one study matched case and control groups. However, in that single study [9], DM was proven to be the most dangerous factor for IPF in the logistic regression model (OR 4.3, 95\% CI 1.9-9.8). Genetic factor, which was considered as one of the covariates according to the guidelines by ATS/ERS [4], was not referred to in any study except one [24]. Additionally, case and control groups in this 


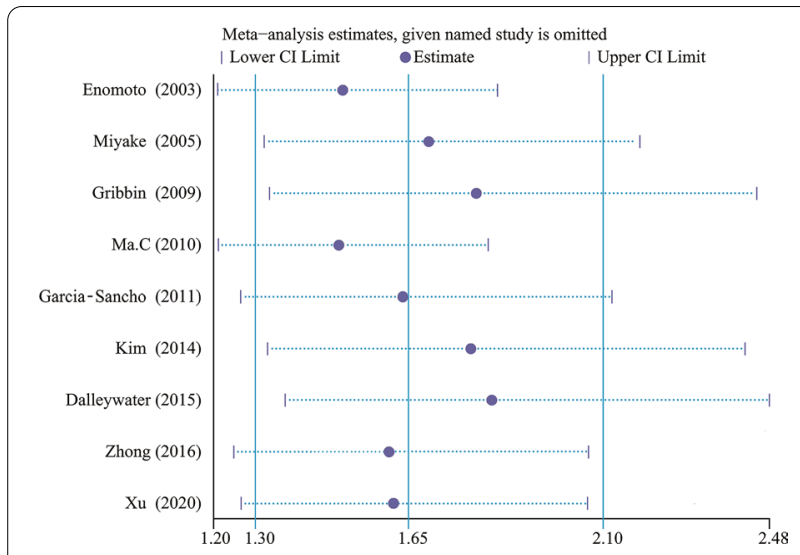

Fig. 4 Sensitivity analyses of the primary meta-analysis. Every odds ratio was located between 1.30 and 2.10 while none of $95 \%$ confidence intervals crossed the invalid line "1", signifying that the result was stable

study were regrettably unmatched. Thus, the impact it had on final conclusions was difficult to evaluate. Publication bias existed $(P=0.016<0.05)$ judged by the Egger's test (Fig. 6).

\section{Discussion}

\section{Main findings and clinical inspiration}

In the present meta-analysis, it was revealed that the prevalence of diabetes was increased markedly in IPF cases compared with controls, which suggests that DM and IPF might be positively associated. However, we noticed that a latest study [31] came to the opposite conclusion. Since all of the included studies are retrospective case-control studies, which are easily affected by recall bias and additionally, the interpretation of the outcome is in the limitation of the significant heterogeneity, which could not be satisfactorily explained, we believe that our conclusion still need further evidence.

Interestingly, a recent review [32] clarified the common features between IPF and pulmonary complications in diabetics. These include clinical characteristics (significant reductions in FVC, FEV1 [33] and $\mathrm{DL}_{\mathrm{CO}}$ [34-38]), HRCT imaging (the frequently presented UIP pattern [39, 40]) and histopathological changes (thickening of the basal lamina of lung capillaries [41, 42], increased amount of collagen in the alveolar walls [43], etc.), all of which indicated that IPF and diabetes are closely related. This conclusion validated the findings of our meta-analysis as well as equipping them with biological plausibility. However, it is still unclear whether a causal relationship exists between DM and IPF.

Therefore, understanding the exact pathological mechanisms is crucial; namely, how persistent hyperglycemia, a known characteristic of diabetes, gradually contributes to the pulmonary lesions. Studies found that a high glucose concentration could result in nonenzymatic glycation with the ultimate formation of advanced glycation end products (AGEs), which may target type IV collagen in the alveolar basement membrane, thicken the basal lamina both in epithelial and capillary of alveoli and eventually lead to a decrease in pulmonary elasticity and compliance [44-46]. This hypothesis has become recognized as an explanation for the pathological abnormalities of interest, including injured pulmonary function in diabetic individuals. Furthermore, some investigators hold the view that oxidative stress (OS), which refers to an imbalance between free radicals and antioxidants in the body, is intimately connected with the onset of IPF. On one hand, OS can directly enhance nonenzymatic glycation [47], but on another, OS participates in the activation of nuclear factor-kappaB (NF-kB) [48],

Table 2 Subgroup analysis

\begin{tabular}{|c|c|c|c|c|c|c|c|c|c|}
\hline \multirow{2}{*}{$\begin{array}{l}\text { Study characteristic } \\
\text { Groups matched by age and sex }[7,8,10,24-27]\end{array}$} & \multirow{2}{*}{$\begin{array}{l}\text { Study } \\
7\end{array}$} & \multicolumn{2}{|c|}{ IPF (D/T) } & \multicolumn{2}{|c|}{$\begin{array}{l}\text { Control } \\
\text { Group (D/T) }\end{array}$} & \multirow{2}{*}{$\begin{array}{l}\text { OR } \\
1.43\end{array}$} & \multirow{2}{*}{$\begin{array}{l}95 \% \mathrm{Cl} \\
1.16-1.76\end{array}$} & \multirow{2}{*}{$\begin{array}{l}P \text { value } \\
P=0.0007\end{array}$} & \multirow{2}{*}{$\begin{array}{l}\text { Heterogeneity } \\
R^{2}=55 \%\end{array}$} \\
\hline & & 698 & 4891 & 2142 & 18,420 & & & & \\
\hline Smoking status matched in both groups $[8-10,25]$ & 4 & 203 & 1581 & 598 & 6138 & 1.52 & $1.05-2.19$ & $P=0.02$ & $P^{2}=65 \%$ \\
\hline Control groups made up of general population $[7,10,25-28]$ & 6 & 721 & 4795 & 2135 & 18,212 & 1.49 & $1.19-1.88$ & $P=0.0007$ & $R^{2}=66 \%$ \\
\hline Control group with pulmonary diseases $[8,9]$ & 2 & 24 & 201 & 23 & 620 & 2.23 & $0.56-8.88$ & $P=0.25$ & $P^{2}=79 \%$ \\
\hline Healthy control group [24] & 1 & 30 & 100 & 50 & 263 & 1.83 & $1.08-3.09$ & $\ldots$ & $\ldots$ \\
\hline Community controls $[7,24]$ & 2 & 47 & 152 & 71 & 447 & 2.50 & $1.24-5.06$ & $P=0.01$ & $R^{2}=59 \%$ \\
\hline Hospital controls [8-10, 25-28] & 7 & 728 & 4944 & 2137 & 18,648 & 1.47 & $1.17-1.84$ & $P=0.008$ & $R^{2}=61 \%$ \\
\hline Diagnosis of IPF based on ATS/ERS criteria [7-9, 24-26] & 6 & 170 & 857 & 402 & 3080 & 2.09 & $1.34-3.29$ & $P=0.001$ & $R^{2}=66 \%$ \\
\hline Diagnosis of DM based on FBG $[7,9,25,26,28]$ & 5 & 193 & 761 & 395 & 2872 & 2.38 & $1.43-3.97$ & $P=0.0009$ & $P^{2}=72 \%$ \\
\hline Diagnosis of DM based on subjective methods $[8,24]$ & 2 & 43 & 204 & 57 & 323 & 1.62 & $1.02-2.58$ & $P=0.04$ & $P^{2}=0$ \\
\hline
\end{tabular}

D: Diabetes. T: Total. IPF: Idiopathic Pulmonary Fibrosis. DM: Diabetes Mellitus. FBG: Fasting Blood Glucose. ATS: American Thoracic Society. ERS: European Respiratory Society 


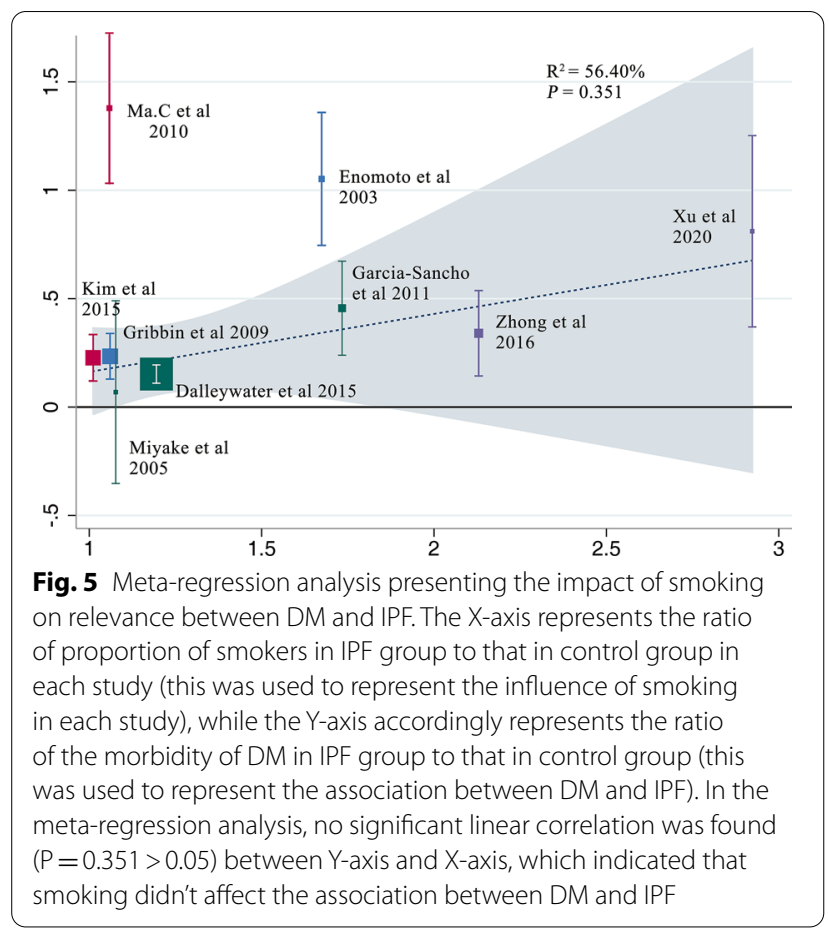

which is presumably the central part in initiating processes of alveolitis. One study [49] shows that inhibiting the activation of the transcription factor NF- $\mathrm{KB}$ could reduce lung injury and fibrosis. Hürdag et al. [50] discovered that OS could decrease superoxide dismutase (SOD), increase nitric oxide synthase (NOS), and contribute to overproduction of nitric oxide $(\mathrm{NO})$ and peroxynitrite $\left(\mathrm{ONOO}^{-}\right)$, potentially giving rise to damage of lung tissue and ultimately pulmonary fibrosis [51, 52]. In addition, inflammatory cytokines play a crucial role, among which transforming growth factor-beta1 (TGF- $\beta 1$ ) attracts the most attention. TGF- $\beta 1$ was found overexpressed in hyperglycemia, which has been documented to promote proliferation and differentiation of fibroblasts, activation of myofibroblasts and deposition of extracellular matrix (ECM) [53-57], all of which will eventually bring about lung fibrosis. In recent years, the relationship between telomere length, DM and IPF has attracted attention. Elevated glucose and increased oxidative stress might interfere with telomerase function, thereby leading to shortened telomere length [58] and a mendelian randomisation study [59] inferred a causal link between shorter telomere length and higher risk of IPF.

Although the possible pathophysiologic mechanisms do explain the disease process, we acknowledge that multiple factors may induce pulmonary fibrosis and that it is also indeterminate to what extend IPF is affected by diabetes. Thus, to solidify the association between DM and IPF, the beneficial effect of antidiabetic therapy should be established. Rangarajan et al. [12] demonstrated that metformin could reverse lung fibrosis in a bleomycin model via AMPK activation, which is also the potential mechanism of metformin in diabetes [60]. The discovery indicated a certain connection between these two diseases and provided a potential evidence on possible benefit of anti-diabetics for the treatment of IPF. Nevertheless, successful therapies in animal models was not particularly efficacious in human studies and a post hoc analysis [16] showed no advantages of metformin when in combination therapy with pirfenidone. Possible explanations may include that AMPK activation is only relevant to certain IPF phenotypes, or insufficient drug concentrations in the lung [61]. Consequently, the effect of antidiabetic treatment in IPF remains uncomfirmed up to now. Since persistent hyperglycemia might participate in the occurrence of pulmonary fibrosis, perhaps future researches could investigate the suitable threshold of blood glucose

Table 3 Potential sources of bias

\begin{tabular}{|c|c|c|c|c|}
\hline \multirow{2}{*}{$\begin{array}{l}\text { Study } \\
\text { Enomoto et al. [7] } 2003\end{array}$} & \multicolumn{2}{|c|}{ Environmental Exposure (IG/CG) } & \multicolumn{2}{|l|}{ Family IPF (IG/CG) } \\
\hline & Not stated & Not stated & Not stated & Not stated \\
\hline Miyake et al. [8] 2005 & $31.7 \%$ & $8.3 \%$ & Not stated & Not stated \\
\hline Gribbin et al. [10] 2009 & Not stated & Not stated & Not stated & Not stated \\
\hline Ma et al. [9] 2010 & $\begin{array}{l}\text { dust } 56.7 \% \\
\text { smoke } 66.0 \% \\
\text { chemicals } 28.9 \%\end{array}$ & $\begin{array}{l}\text { dust } 52.1 \% \\
\text { smoke } 69.3 \% \\
\text { chemicals } 21.4 \%\end{array}$ & Not stated & Not stated \\
\hline Garcia-Sancho et al. [24] 2011 & Matched by place of residence & Matched by place of residence & $20 \%$ & $8.7 \%$ \\
\hline Kim et al. [25] 2015 & Not stated & Not stated & Not stated & Not stated \\
\hline Dalleywater et al. [27] 2015 & Not stated & Not stated & Not stated & Not stated \\
\hline Zhong et al. [28] 2016 & Not stated & Not stated & Not stated & Not stated \\
\hline Xu et al. [26] 2020 & Not stated & Not stated & Not stated & Not stated \\
\hline
\end{tabular}

IG IPF Group, CG Control Group 


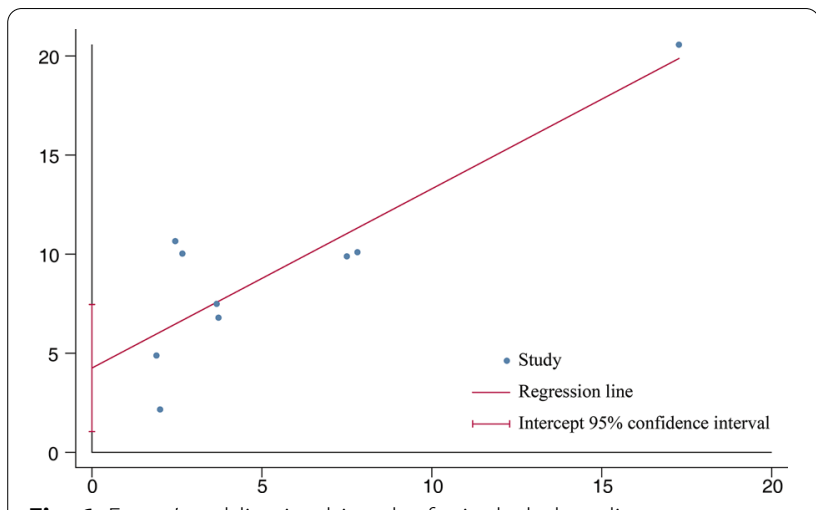

Fig. 6 Egger's publication bias plot for included studies for IPF and figure out whether timely and effective hypoglycemic therapy would prevent the incidence of the disease. We expect such findings could further strengthen the evidence linking IPF with DM.

\section{Strengths and limitations}

In our meta-analysis, we screened literatures in strict accordance with inclusion and exclusion criteria, designed the study with high quality, and finally demonstrated that DM and IPF are very likely interrelated. Nevertheless, there remain several limitations in our study. Firstly, the heterogeneity was significant, and a reasonable interpretation is still absent. The wide range of prevalence of DM (from 10 to $61 \%$ in IPF groups and from 3 to $43 \%$ in control groups) in the studies has attracted our attention, which could be responsible for major heterogeneity; we assumed this to be secondary to multiple factors including diagnostic criteria of diabetes (subjective or objective methods) and IPF (differences of diagnostic criteria in different guidelines), selection of populations (with or without underlying diseases), and regional differences. However, the internal causal relationship has not been established to date. Secondly, given that the result is based on case-control studies, which are susceptible to confounding factors, the potential sources of biases have always been a focus. Even though influence of smoking, age, and gender was ruled out in our bias analysis, other covariates such as genetic factor might also cloud the association between DM and IPF, especially considering that at least $30 \%$ of patients have predisposing genetic factors which could increase the risk of pulmonary fibrosis [62-64]. Besides, two studies [10, 27] from the UK are based on the THIN database (in Gribbin's research, IPF cases are from the period 1991-2003 while in Dalleywat's, cases are from 2000 to 2011), which may be one of the contributory reasons of the notable publication bias, and repeated cases might cause type I errors (false positive conclusions).

\section{Conclusion}

The association between diabetes and IPF was briefly referred to in ATS/ERS clinical practice guideline updated in 2011 [65], but not in the newest edition [4] perhaps owing to the contradiction of existing evidence. Although our study suggested that IPF and DM might be relevant, the causal relationship cannot be completely established up to now. Thus, more evidences are still required.

\section{Appendix}

We used Multi-Field Search in medline.

1. (pulmonary fibrosis and diabetes).ti.

2. pulmonary fibrosis.ti. and diabetes.ab.

3. pulmonary fibrosis.ti. and diabetes.tw.

We used Advanced search in Cochrane Library.

1. pulmonary fibrosis in Title Abstract Keyword AND diabetes in Title Abstract Keyword

2. pulmonary fibrosis in Title Abstract Keyword AND diabetes in All Text

We used Quick Search in Embase.

1. 'pulmonary fibrosis':ti AND diabetes:ti,ab,kw

2. 'pulmonary fibrosis':ti AND 'risk factors':ti,ab,kw

We used Advanced search in Web of Science.

1. $(\mathrm{TI}=$ (pulmonary fibrosis $)) \mathrm{AND} \mathrm{TI}=$ (diabetes)

2. $(\mathrm{TI}=$ (pulmonary fibrosis $)) \mathrm{AND} \mathrm{AB}=$ (diabetes)

3. $(\mathrm{TI}=$ (pulmonary fibrosis $)) \mathrm{AND} \mathrm{TS}=$ (diabetes $)$

We used Advanced search in China National Knowledge Infrastructure.

1. (((idiopathic pulmonary fibrosis[Title]) OR (pulmonary fibrosis[Title])) OR (IPF[Title])) AND (diabetes[Title/Keyword/Abstract])

2. (((idiopathic pulmonary fibrosis[Title]) OR (pulmonary fibrosis[Title])) OR (IPF[Title])) AND (diabetes[Text Word]) 


\section{Abbreviations}

ATS: American Thoracic Society; DLCO: Diffusion capacity for carbon monoxide of the lung; DM: Diabetes mellitus; ERS: European Respiratory Society; FEV1: Forced expiratory volume in the first second; FVC: Forced vital capcacit; HRCT : High-resolution computed tomography; ILD: Interstitial lung disease; IPF: Idiopathic pulmonary fibrosis; NF-Kb: Nuclear factor-kappaB; NOS: Newcastle-Ottawa Scale; TGF- $\beta 1$ : Transforming growth factor- $\beta 1$; THIN: The Health Improvement Network; TSA: Trial sequential analysis; UIP: Usual interstitia pneumonia.

\section{Acknowledgements}

Not applicable.

\section{Authors' contributions}

$\mathrm{XZ}$ and $\mathrm{HH}$ contributed conception, design, and quality control of the study. LB was in charge of literature search, data extraction, and manuscript writing. LZ and TP helped with data extraction. WW and DW managed data analysis. Cassidy Turner edited the language. All authors read and approved the final manuscript.

\section{Funding}

This study was supported by National Nature Science Foundation of China (Grant No. 82074358).

\section{Availability of data and materials}

All data generated or analysed during this study are included in these published article [7-10, 24-28].

\section{Ethics approval and consent to participate}

Not applicable.

\section{Consent for publication}

Not applicable.

\section{Competing interests}

All of the authors have no competing interests.

\section{Author details}

${ }^{1}$ Affiliated Hospital of Nanjing University of Chinese Medicine, Nanjing 210029, China. ${ }^{2}$ Department of GCP Research Center, Jiangsu Province Hospital of Chinese Medicine, Nanjing 210029, China. ${ }^{3}$ Arizona Metabolomics Laboratory, College of Health Solutions, Arizona State University, Scottsdale, AZ, USA. ${ }^{4}$ Department of Respiratory Medicine, Jiangsu Province Hospital of Chinese Medicine, 155 Hanzhong Road, Nanjing 210029, Jiangsu Province, People's Republic of China.

\section{Received: 24 February 2021 Accepted: 26 May 2021}

Published online: 08 June 2021

\section{References}

1. Raghu G, Chen SY, Hou Q, Yeh WS, Collard HR. Incidence and prevalence of idiopathic pulmonary fibrosis in US adults 18-64 years old. Eur Respir J. 2016:48:179-86.

2. Strongman H, Kausar I. Maher TJAit: incidence prevalence, and survival of patients with idiopathic pulmonary fibrosis in the UK. Adv Therapy. 2018;35:724-36

3. Behr J, Prasse A, Wirtz H, Koschel D, Pittrow D, Held M, Klotsche J, Andreas S, Claussen M, Grohé C, et al. Survival and course of lung function in the presence or absence of antifibrotic treatment in patients with idiopathic pulmonary fibrosis: long-term results of the INSIGHTS-IPF registry. Eur Respir J. 2020;56:2.

4. Raghu G, Remy-Jardin M, Myers JL, Richeldi L, Ryerson CJ, Lederer DJ, Behr J, Cottin V, Danoff SK, Morell F, et al. Diagnosis of idiopathic pulmonary fibrosis. An Official ATS/ERS/JRS/ALAT Clinical Practice Guideline. Am J Respir Crit Care Med. 2018;198:44-68.

5. Marshall RP, McAnulty RJ, Laurent GJ. The pathogenesis of pulmonary fibrosis: is there a fibrosis gene? Int J Biochem Cell Biol. 1997;29:107-20.
6. Pardo A, Selman M. The interplay of the genetic architecture, aging, and environmental factors in the pathogenesis of idiopathic pulmonary fibrosis. Am J Respir Cell Mol Biol. 2020;64:163-72.

7. Enomoto T, Usuki J, Azuma A, Nakagawa T, Kudoh S. Diabetes mellitus may increase risk for idiopathic pulmonary fibrosis. Chest. 2003;123:2007-11.

8. Miyake Y, Sasaki S, Yokoyama T, Chida K, Azuma A, Suda T, Kudoh S, Sakamoto N, Okamoto K, Kobashi G, et al. Case-control study of medical history and idiopathic pulmonary fibrosis in Japan. Respirology. 2005;10:504-9.

9. García-Sancho Figueroa MC, Carrillo G, Pérez-Padilla R, Fernández-Plata MR, Buendía-Roldán I, Vargas MH, Selman M. Risk factors for idiopathic pulmonary fibrosis in a Mexican population. A case-control study. Respir Med. 2010;104:305-9.

10. Gribbin J, Hubbard R, Smith C. Role of diabetes mellitus and gastrooesophageal reflux in the aetiology of idiopathic pulmonary fibrosis. Respir Med. 2009;103:927-31.

11. Gamad N, Malik S, Suchal K, Vasisht S, Tomar A, Arava S, Arya DS, Bhatia J. Metformin alleviates bleomycin-induced pulmonary fibrosis in rats: pharmacological effects and molecular mechanisms. Biomed Pharmacother. 2018;97:1544-53.

12. Rangarajan S, Bone NB, Zmijewska AA, Jiang S, Park DW, Bernard K, Locy ML, Ravi S, Deshane J, Mannon RB, et al. Metformin reverses established lung fibrosis in a bleomycin model. Nat Med. 2018;24:1121-7.

13. Wang Y, Lin C, Han R, Lu C, Li L, Hu C, Feng M, Chen H, He Y. Metformin attenuates TGF- $\beta 1$-induced pulmonary fibrosis through inhibition of transglutaminase 2 and subsequent TGF- $\beta$ pathways. 3 Biotech. 2020;10:287.

14. Xiao H, Huang X, Wang S, Liu Z, Dong R, Song D, Dai H. Metformin ameliorates bleomycin-induced pulmonary fibrosis in mice by suppressing IGF-1. Am J Transl Res. 2020;12:940-9.

15. Kheirollahi V, Wasnick RM, Biasin V, Vazquez-Armendariz Al, Chu X, Moiseenko A, Weiss A, Wilhelm J, Zhang JS, Kwapiszewska G, et al. Metformin induces lipogenic differentiation in myofibroblasts to reverse lung fibrosis. Nat Commun. 2019:10:2987.

16. Spagnolo P, Kreuter M, Maher TM, Wuyts W, Bonella F, Corte TJ, Kopf S, Weycker D, Kirchgaessler KU, Ryerson CJ. Metformin does not affect clinically relevant outcomes in patients with idiopathic pulmonary fibrosis. Respiration. 2018;96:314-22.

17. Kreuter M, Lederer DJ, Cottin V, Kahn N, Ley B, Vancheri C, Weycker D, Atwood M, Kirchgaessler KU, Ryerson CJ. Concomitant medications and clinical outcomes in idiopathic pulmonary fibrosis. Eur Respir J. 2019:54:6.

18. Stroup DF, Berlin JA, Morton SC, Olkin I, Williamson GD, Rennie D, Moher D, Becker BJ, Sipe TA, Thacker SB. Meta-analysis of observational studies in epidemiology: a proposal for reporting. Meta-analysis Of Observational Studies in Epidemiology (MOOSE) group. JAMA. 2000;283:2008-12.

19. Moher D, Liberati A, Tetzlaff J, Altman DG. Preferred reporting items for systematic reviews and meta-analyses: the PRISMA statement. J Clin Epidemiol. 2009;62:1006-12.

20. Wells GA SB, O'Connell D, et al: The Newcastle-Ottawa Scale (NOS) for assessing the quality of nonrandomised studies in meta-analyses.

21. Brok J, Thorlund K, Gluud C, Wetterslev J. Trial sequential analysis reveals insufficient information size and potentially false positive results in many meta-analyses. J Clin Epidemiol. 2008;61:763-9.

22. Brok J, Thorlund K, Wetterslev J, Gluud C. Apparently conclusive metaanalyses may be inconclusive-Trial sequential analysis adjustment of random error risk due to repetitive testing of accumulating data in apparently conclusive neonatal meta-analyses. Int J Epidemiol. 2009;38:287-98.

23. Egger M, Davey Smith G, Schneider M, Minder C. Bias in meta-analysis detected by a simple, graphical test. BMJ. 1997;315:629-34.

24. García-Sancho C, Buendía-Roldán I, Fernández-Plata MR, Navarro C, Pérez-Padilla R, Vargas MH, Loyd JE, Selman M. Familial pulmonary fibrosis is the strongest risk factor for idiopathic pulmonary fibrosis. Respir Med. 2011;105:1902-7.

25. Kim WY, Mok Y, Kim GW, Baek SJ, Yun YD, Jee SH, Kim DS. Association between idiopathic pulmonary fibrosis and coronary artery disease: a case-control study and cohort analysis. Sarcoidosis Vasc Diffuse Lung Dis. 2015;31:289-96.

26. Xu J. shao-xia L: Study on association of idiopathic pulmonary fibrosis with diabetes mellitus. J Med Forum. 2020;41:58-62. 
27. Dalleywater W, Powell HA, Hubbard RB, Navaratnam V. Risk factors for cardiovascular disease in people with idiopathic pulmonary fibrosis: a population-based study. Chest. 2015;147:150-6.

28. Xie Z, He Y, Sun Y, Lin Z, Yang M, Liu Q, Liu S. Association between pulmonary fibrosis and osteoporosis in the elderly people: a case-control study. Medicine (Baltimore). 2016;95:5239.

29. Behr J, Kreuter M, Hoeper MM, Wirtz H, Klotsche J, Koschel D, Andreas S, Claussen M, Grohé C, Wilkens H, et al. Management of patients with idiopathic pulmonary fibrosis in clinical practice: the INSIGHTS-IPF registry. Eur Respir J. 2015;46:186-96.

30. Baumgartner KB, Samet JM, Coultas DB, Stidley CA, Hunt WC, Colby TV, Waldron JA. Occupational and environmental risk factors for idiopathic pulmonary fibrosis: a multicenter case-control study. Collaborating Centers. Am J Epidemiol. 2000;152:307-15.

31. Navaratnam V, Davis TME, Hubbard R, Davis WA. Incidence and predictors of idiopathic pulmonary fibrosis complicating Type 2 diabetes: the Fremantle Diabetes Study Phase I. Intern Med J. 2021;51:276-9.

32. Wang $D, M a Y$, Tong $X$, Zhang $Y$, Fan $H$. Diabetes mellitus contributes to idiopathic pulmonary fibrosis: a review from clinical appearance to possible pathogenesis. Front Public Health. 2020:8:196.

33. Yeh HC, Punjabi NM, Wang NY, Pankow JS, Duncan BB, Cox CE, Selvin E, Brancati FL. Cross-sectional and prospective study of lung function in adults with type 2 diabetes: the Atherosclerosis Risk in Communities (ARIC) study. Diabetes Care. 2008;31:741-6.

34. Marvisi M, Bartolini L, del Borrello P, Brianti M, Marani G, Guariglia A, Cuomo A. Pulmonary function in non-insulin-dependent diabetes mellitus. Respiration. 2001;68:268-72.

35. Davis WA, Knuiman M, Kendall P, Grange V, Davis TM. Glycemic exposure is associated with reduced pulmonary function in type 2 diabetes: the Fremantle Diabetes Study. Diabetes Care. 2004;27:752-7.

36. Sonoda N, Morimoto A, Tatsumi Y, Asayama K, Ohkubo T, Izawa S, Ohno Y. A prospective study of the impact of diabetes mellitus on restrictive and obstructive lung function impairment: The Saku study. Metabolism. 2018;82:58-64.

37. van den Borst B, Gosker HR, Zeegers MP, Schols AM. Pulmonary function in diabetes: a metaanalysis. Chest. 2010;138:393-406.

38. Klein OL, Krishnan JA, Glick S, Smith LJ. Systematic review of the association between lung function and Type 2 diabetes mellitus. Diabet Med. 2010;27:977-87

39. Hu Y, Ma Z, Guo Z, Zhao F, Wang Y, Cai L, Yang J. Type 1 diabetes mellitus is an independent risk factor for pulmonary fibrosis. Cell Biochem Biophys. 2014;70:1385-91.

40. Kim YJ, Park JW, Kyung SY, Lee SP, Chung MP, Kim YH, Lee JH, Kim YC, Ryu $J S$, Lee $H L$, et al. Clinical characteristics of idiopathic pulmonary fibrosis patients with diabetes mellitus: the national survey in Korea from 2003 to 2007. J Korean Med Sci. 2012;27:756-60.

41. Weynand B, Jonckheere A, Frans A, Rahier J. Diabetes mellitus induces a thickening of the pulmonary basal lamina. Respiration. 1999;66:14-9.

42. Watanabe K, Senju S, Toyoshima H, Yoshida M. Thickness of the basement membrane of bronchial epithelial cells in lung diseases as determined by transbronchial biopsy. Respir Med. 1997;91:406-10.

43. Fariña J, Furió V, Fernandez-Aceñero MJ, Muzas MA. Nodular fibrosis of the lung in diabetes mellitus. Virchows Arch. 1995;427:61-3.

44. Vlassara H, Bucala R, Striker L. Pathogenic effects of advanced glycosylation: biochemical, biologic, and clinical implications for diabetes and aging. Lab Invest. 1994;70:138-51.

45. McKeever TM, Weston PJ, Hubbard R, Fogarty A. Lung function and glucose metabolism: an analysis of data from the Third National Health and Nutrition Examination Survey. Am J Epidemiol. 2005;161:546-56.

46. Schmidt AM, Hori O, Cao R, Yan SD, Brett J, Wautier JL, Ogawa S, Kuwabara K, Matsumoto M, Stern D. RAGE: a novel cellular receptor for advanced glycation end products. Diabetes. 1996;45(Suppl 3):S77-80.

47. Oztay F, Kandil A, Gurel E, Ustunova S, Kapucu A, Balci H, Akgun-Dar $\mathrm{K}$, Demirci $\mathrm{C}$. The relationship between nitric oxide and leptin in the lung of rat with streptozotocin-induced diabetes. Cell Biochem Funct. 2008;26:162-71.

48. Li KC, Ho YL, Chen CY, Hsieh WT, Chang YS, Huang GJ. Lobeline improves acute lung injury via nuclear factor-kB-signaling pathway and oxidative stress. Respir Physiol Neurobiol. 2016;225:19-30.
49. Gurujeyalakshmi G, Wang Y, Giri SN. Taurine and niacin block lung injury and fibrosis by down-regulating bleomycin-induced activation of transcription nuclear factor-kappaB in mice. J Pharmacol Exp Ther. 2000;293:82-90.

50. Hürdağ C, Uyaner I, Gürel E, Utkusavas A, Atukeren P, Demirci C. The effect of alpha-lipoic acid on NOS dispersion in the lung of streptozotocininduced diabetic rats. J Diabetes Comp. 2008:22:56-61.

51. Schwartz MD, Moore EE, Moore FA, Shenkar R, Moine P, Haenel JB, Abraham E. Nuclear factor-kappa B is activated in alveolar macrophages from patients with acute respiratory distress syndrome. Crit Care Med. 1996;24:1285-92

52. He Z, Li B, Yu L, Liu Q, Zhong N, Ran P. Suppression of oxidant-induced glutathione synthesis by erythromycin in human bronchial epithelial cells. Respiration. 2008;75:202-9.

53. Tarantal AF, Chen H, Shi TT, Lu CH, Fang AB, Buckley S, Kolb M, Gauldie J, Warburton D, Shi W. Overexpression of transforming growth factor-beta1 in fetal monkey lung results in prenatal pulmonary fibrosis. Eur Respir J. 2010;36:907-14.

54. Border WA, Noble NA. Transforming growth factor beta in tissue fibrosis. N Engl J Med. 1994;331:1286-92.

55. Fernandez IE, Eickelberg O. The impact of TGF- $\beta$ on lung fibrosis: from targeting to biomarkers. Proc Am Thorac Soc. 2012;9:111-6.

56. Zhang YE. Non-smad signaling pathways of the TGF- $\beta$ family. Cold Spring Harb Perspect Biol. 2017;9:1.

57. Massagué J. TGF $\beta$ signalling in context. Nat Rev Mol Cell Biol. 2012;13:616-30.

58. Cheng F, Carroll L, Joglekar MV, Januszewski AS, Wong KK, Hardikar AA, Jenkins AJ, Ma RCW. Diabetes, metabolic disease, and telomere length. Lancet Diabetes Endocrinol. 2021:9:117-26.

59. Duckworth A, Gibbons MA, Allen RJ, Almond H, Beaumont RN, Wood AR, Lunnon K, Lindsay MA, Wain LV, Tyrrell J, Scotton CJ. Telomere length and risk of idiopathic pulmonary fibrosis and chronic obstructive pulmonary disease: a mendelian randomisation study. Lancet Respir Med. 2021;9:285-94

60. Zhang CS, Li M, Ma T, Zong Y, Cui J, Feng JW, Wu YQ, Lin SY, Lin SC. Metformin activates AMPK through the lysosomal pathway. Cell Metab. 2016;24:521-2.

61. Manning EP, Losier A, Emeagwali N, Ryu C, Honiden S. New applications of old drugs as novel therapies in idiopathic pulmonary fibrosis. Metformin, hydroxychloroquine, and thyroid hormone. Am J Respir Crit Care Med. 2019;199:1561-3.

62. Allen RJ, Porte J, Braybrooke R, Flores C, Fingerlin TE, Oldham JM, Guillen-Guio B, Ma SF, Okamoto T, John AE, et al. Genetic variants associated with susceptibility to idiopathic pulmonary fibrosis in people of European ancestry: a genome-wide association study. Lancet Respir Med. 2017:5:869-80.

63. Fingerlin TE, Murphy E, Zhang W, Peljto AL, Brown KK, Steele MP, Loyd JE, Cosgrove GP, Lynch D, Groshong S, et al. Genome-wide association study identifies multiple susceptibility loci for pulmonary fibrosis. Nat Genet. 2013;45:613-20.

64. Peljto AL, Zhang Y, Fingerlin TE, Ma SF, Garcia JG, Richards TJ, Silveira LJ, Lindell KO, Steele MP, Loyd JE, et al. Association between the MUC5B promoter polymorphism and survival in patients with idiopathic pulmonary fibrosis. JAMA. 2013;309:2232-9.

65. Raghu G, Collard HR, Egan JJ, Martinez FJ, Behr J, Brown KK, Colby TV, Cordier JF, Flaherty KR, Lasky JA, et al. An official ATS/ERS/JRS/ALAT statement: idiopathic pulmonary fibrosis: evidence-based guidelines for diagnosis and management. Am J Respir Crit Care Med. 2011;183:788-824.

66. American Thoracic Society. Idiopathic pulmonary fibrosis: diagnosis and treatment International consensus statement. American Thoracic Society (ATS), and the European Respiratory Society (ERS). Am J Respir Crit Care Med. 2000;161:646-64.

\section{Publisher's Note}

Springer Nature remains neutral with regard to jurisdictional claims in published maps and institutional affiliations. 